\section{A Relevância e os Desafios da Indústria de Seguros na Administração Contemporânea: Um Chamamento aos Pesquisadores}

\author{
The Relevance and Challenges of the Insurance Industry in Contemporary
} Administration: A Call for Researchers

\begin{abstract}
João Vinícius de França Carvalho*1 Eduardo Flores ${ }^{10}$ Emiliano A. Valdez ${ }^{2}$
\end{abstract}

\section{CONTEXTUALIZAÇÃO E UMA PROPOSTA DE AGENDA DE PESQUISA PARA O SETOR}

A indústria de seguros é um dos segmentos mais relevantes para o desenvolvimento econômico sustentável, não apenas porque protege o patrimônio da sociedade, mas também por fomentar a formação de provisóes e reservas de longo prazo. Assim, é possível garantir que os avanços de distribuição de renda, bem como o consumo das famílias, não retroajam diante da materialização de cenários adversos. Ao promover uma retroalimentaçáo virtuosa entre a atividade produtiva e o legítimo interesse social, este setor desempenha um papel central na promoção do bem-estar coletivo. Portanto, as Ciências Atuariais podem colaborar fortemente no desenvolvimento da Administração Contemporânea (Bispo, 2022).

As Ciências Atuariais têm o risco como seu principal objeto de estudo. Há riscos de qualquer origem ou natureza. Uma pessoa corre o risco de adoecer ou ferir-se, limitando a sua capacidade de geraçáo de rendimentos ou perdendo os seus bens e propriedades. Uma pessoa corre o risco de morte prematura, deixando uma família enlutada que pode ser financeiramente dependente. As empresas, por sua vez, lidam com a possibilidade de perder sua capacidade operacional em decorrência de imprevistos. Há a possibilidade adicional de danos causados a terceiros náo diretamente vinculados à ação.

Os contratos de seguro são instrumentos financeiros de proteção patrimonial contra riscos com probabilidade de ocorrência baixa, mas que trazem graves prejuízos, deixando os afetados com prejuízos que podem levar à ruína financeira. A indústria de seguros e os gestores de risco interagem com diferentes áreas de atuação: Finanças, Economia, Contabilidade, Probabilidade, Estatística, Ciência da Computação, entre outras.

No Brasil, o setor de seguros vem apresentando crescente importância econômica, visto que existe uma demanda crescente por proteção. Entre 2000 e 2018, o mercado brasileiro de seguros teve um aumento real de $69 \%$ nos prêmios ganhos, o que representa um crescimento médio em torno de 3\% ao ano, passando de $1,5 \%$ para quase $4 \%$ do PIB.

\footnotetext{
* Autor Correspondente.

1. Universidade de São Paulo, Faculdade de Economia, Administração, Contabilidade e Atuária, São Paulo, SP, Brasil.

2. University of Connecticut, Storrs, Connecticut, EUA.
}

Como citar: Carvalho, J. V. F., Flores, E., \& Valdez, E. A. (2022). A relevância e os desafios da indústria de seguros na administração contemporânea: Um chamamento aos pesquisadores. Revista de Administração Contemporânea, 26(3), e210313. https://doi.org/10.1590/1982-7849rac2022210313.por 
No entanto, a evoluçáo dos trabalhos de pesquisa não é tão rápida quanto o desenvolvimento dessa indústria, de modo que os estudiosos brasileiros não têm focado suas pesquisas naqueles que oferecem contratos: as seguradoras. No mesmo período (2000-2018), o número total de seguradoras ativas (cerca de 200, considerando tanto as seguradoras como as resseguradoras a operar no país) diminuiu 11\%. Afinal, eles oferecem o mercado para a gestão dos recursos financeiros coletivos de forma a proporcionar proteção financeira contra os riscos enfrentados pela sociedade. Por outro lado, são poucos os periódicos locais que publicam artigos sobre $o$ assunto.

Nesse contexto, tanto as seguradoras quanto os pesquisadores devem lidar com modelos qualitativos e quantitativos para gerenciar os riscos de diferentes fontes (subscrição, operacional, jurídico, financeiro e de crédito). Isso ajuda a garantir que a solvência financeira no longo prazo possa ser mantida e uma gama adicional de oportunidades possa ser explorada.

Sem a pretensão de uma análise exaustiva, mas com o intuito de fomentar o debate e, sobretudo, a pesquisa acadêmica de elevada qualidade, é possível conjecturar que não há desenvolvimento socioeconômico consistente e inclusivo sem que o mercado segurador esteja profundamente associado a isto. Um editorial recente da Revista Contabilidade \& Finanças, do Departamento de Contabilidade e Atuária da FEA-USP, já chamava a atenção para o crescimento dessa área no Brasil (Afonso, 2020).

Mais apropriadamente sob a égide social, os seguros cumprem distintas funçôes, dentre as quais se destacam: (a) a manutenção patrimonial dos indivíduos por meio dos produtos vinculados a coberturas de danos (Euphasio Junior \& Carvalho, 2022); (b) o acúmulo de poupança visando a financiar os pagamentos de aposentadorias e pensóes, seja na esfera da previdência social (Afonso \& Carvalho, 2021), seja na previdência complementar; e (c) o amplo acesso à rede privada de hospitais por meio de planos e seguros de saúde (Areias \& Carvalho, 2021). Em suma, trata-se de um setor inteiramente voltado ao oferecimento de garantias essenciais para que as naçóes possam se desenvolver de forma próspera.

Sob a perspectiva das entidades empresariais, o mercado segurador assume papel de vanguarda na medida em que mitiga os riscos vinculados às perdas patrimoniais, garantindo tranquilidade para que os gestores corporativos tomem decisōes (Rensi \& Carvalho, 2021), retroalimentando um ciclo virtuoso relativo aos ganhos advindos da especialização em nichos econômicos distintos.

Ocorre que os desafios da indústria de seguros na contemporaneidade demandam da pesquisa acadêmica de ponta uma relaçáo de parceria, posto que o rigor metodológico, aliado à seleçáo de temas relevantes para o setor, tem o condáo de permitir que a indústria avance de forma a promover o máximo bem-estar coletivo possível. A seguir, listamos, de forma não exaustiva, alguns dos principais desafios que o mercado segurador já enfrenta e que cada vez mais demandarão atenção dos pesquisadores. Além de os problemas a serem resolvidos serem interdisciplinares, será exigido esforço de aproximação de diversas áreas do conhecimento, como Economia, Contabilidade, Administração e Estatística. Em conjunto, as diferentes visões de mundo, utilizando ferramentas modernas, poderão apresentar soluções robustas para superar os obstáculos.

\section{Reflexos na dinâmica financeira das entidades previdenciárias devido à redução da taxa de natalidade e pelo aumento da longevidade - Binômio natalidade-longevidade}

A dinâmica financeira intertemporal do mercado segurador impóe aos gestores dessas entidades a plena atençáo ao volume de reservas - ativos financeiros - que tenham por finalidade fazer frente às saídas de caixa assumidas pelas companhias que operam tanto com os ramos de vida (e.g., planos previdenciários) quanto com os ramos de não vida (e.g., seguros de danos).

Mas nos seguros de vida e previdência essa gestáo é particularmente mais complexa por envolver períodos estendidos. Junte-se o fato de que as alterações demográficas verificadas nos últimos cinquenta anos vêm apresentando taxas decrescentes de natalidade de uma série de nações (e o Brasil não é diferente). Em sentido oposto, são observados sucessivos crescimentos da longevidade média, justificados pelo desenvolvimento tecnológico e pela mudança de comportamentos a respeito da prevenção de doenças, ambos atributos que contribuem para ampliação da vida humana (Cipriani \& Fioroni, 2019).

A conjugação desses fatores torna a gestão intertemporal seriamente desafiadora para as entidades previdenciárias na medida em que esse setor depende dos recebimentos de contribuiçóes dos mais jovens para fazer frente aos pagamentos devidos aos indivíduos que já gozam de suas aposentadorias (no regime pay-as-you-go) ou acumulação financeira durante a fase ativa para consumo quando as pessoas pararem de trabalhar (no regime fullyfunded). Contudo, à medida que a base da pirâmide demográfica se restringe, e os beneficiários alcançam idades na média mais longevas, é possível afirmar que os ativos dessas entidades se reduzem enquanto os passivos se expandem, gerando o risco de um perigoso desequilíbrio do patrimônio social dessas organizações. 
Portanto, a inclusáo dessa temática na agenda de estudos dos pesquisadores focados no mercado securitário e em assuntos correlatos é atributo de primeira ordem a fim de que autoridades governamentais, empresas privadas, bem como indivíduos poupadores, possam antever problemas advindos do binômio "natalidade-longevidade".

\section{Implicações da redução das taxas} básicas de juros na formação das reservas financeiras das entidades securitárias

Por força de aspectos regulatórios, expressiva parte das aplicaçóes financeiras realizadas pelo mercado segurador se concentra em títulos da dívida pública federal. Embora essa constataçáo náo se limite somente ao ambiente brasileiro (especificamente no Brasil, a res. 4.444/2015 do Banco Central do Brasil é o dispositivo legal que determina os ativos garantidores admissíveis), práticas similares estendem-se para outras jurisdições, uma vez que títulos governamentais possuem alta liquidez e segurança creditícia. Assim, em teoria, não apresentam o risco de não oferecer remuneração nominal.

Ocorreque os títulos públicos possuem os seus retornos atrelados às taxas básicas de juros de cada país. Em algumas localidades essas taxas têm se mostrado em patamares tâo baixos que, quando descontada a inflação compatível com o período, tem-se que o retorno efetivo desses investimentos é próximo de nulo ou negativo em determinadas ocasióes. É dizer: os juros reais de aplicaçôes em títulos de dívidas públicas não são suficientes para recomposiçáo do capital investido subtraindo-se o efeito inflacionário.

Por essa razão, a manutenção das taxas básicas de juros em patamares baixos e a imposição de alocação quase exclusivamente por meio de investimentos em títulos governamentais impóem ao mercado segurador uma restrição de baixa rentabilidade financeira, inadequada para os riscos assumidos. Como consequência, a vantagem de rentabilização de estoque de capital de longo prazo não é compatível com a remuneração necessária para manutenção da solvência financeira dessas organizaçóes.

Por outro lado, há evidências de que taxas de juros elevadas demais inibem o desenvolvimento de determinados segmentos securitários (Flores, Carvalho, \& Sampaio, 2021), fazendo com que as receitas financeiras sejam mais vantajosas do que a própria operaçáo de subscrição de seguros. Esse fator pode, inclusive, inibir a formação de um mercado segurador competitivo e focado no oferecimento de produtos que atendam às demandas dos seus contratantes.

Portanto, é fundamental e necessária a confecção de estudos que atraiam a atenção dos agentes reguladores para o fato de que as entidades securitárias necessitam de maiores graus de liberdade para gestão ativa dos seus portfólios de investimentos. Essa é mais uma contribuição que as pesquisas acadêmicas de elevada qualidade metodológica podem fornecer: a finalidade precípua dos ativos garantidores das entidades securitárias não reside no financiamento da dívida pública federal, mas na acumulaçáo de recursos para atender às demandas dos diferentes stakeholders: participantes ativos e beneficiários, acionistas e, em última instância, a sociedade.

\section{Sandbox no mercado segurador e a necessidade de se desenvolver novos produtos}

A inovação no mercado segurador é palavra de ordem. Desde o aperfeiçoamento dos produtos já existentes até a formulação de novos instrumentos de proteção, verifica-se que a indústria de seguros vem passando por uma profunda transmutação, sobretudo por conta das inúmeras possibilidades oferecidas pelas recentes tecnologias de coleta, processamento e análise de dados.

$\mathrm{O}$ advento do big data tem permitido que as bases de dados de entidades securitárias sejam expandidas, possibilitando a análise de fatores e variáveis que antes eram intratáveis por modelos estatísticos e atuariais tradicionais. Com o desenvolvimento de algoritmos de aprendizagem profunda e técnicas sofisticadas de aprendizagem de máquina, é possível ter formas mais céleres de tarifação atuarial e monitoramento de carteiras (Quan \& Valdez, 2018). Isso ajuda a melhorar a oferta de produtos mais adequados ao perfil idiossincrático de cada segurado.

Atributo de igual relevância para as atuais mudanças experimentadas na indústria de seguros é a redução da participação estatal no provimento de certas coberturas sociais. Ao aumentar a participação da iniciativa privada no provimento de produtos que ajudem a mitigar riscos que reduzem o bem-estar social, pode-se acelerar o desenvolvimento de novos produtos. Seguros cibernéticos (Xu \& Hua, 2019), paramétricos (Lin \& Kwon, 2020), microsseguros para populaçôes vulneráveis (Cole, 2015), entre outras modalidades, estáo na agenda mundial de pesquisas e parecem fazer parte do futuro de um mundo mais protegido.

Por fim, mas não menos relevante, os desafios da mudança climática têm se apresentado para o mercado segurador como uma expressiva oportunidade para que o segmento ofereça soluções factíveis para que a sociedade enfrente os riscos de uma nova configuração geoclimática (Broberg, 2020). Alternativas como o flood insurance podem proteger patrimônios de famílias inteiras contra desastres naturais, os quais tendem geralmente a afetar a camada de indivíduos socialmente mais vulneráveis (Mendes-da-Silva, Lucas, \& Carvalho, 2021). 


\section{SÍNTESE DOS TRABALHOS QUE O LEITOR ENCONTRARÁ NESTA EDIÇÃO ESPECIAL SOBRE A INDÚSTRIA DE SEGUROS}

Antes dos breves comentários sobre os adensados estudos que compóem este edital especial, gostaríamos de agradecer aos editores-chefes da Revista de Administração Contemporânea, na figura do Professor Wesley Mendesda-Silva (ex-editor-chefe) e do Professor Marcelo de Souza Bispo (atual editor-chefe), pelo convite que nos foi formulado no ano de 2020 para que conduzíssemos esta edição especial sobre a indústria de seguros. Nosso muito obrigado pela oportunidade que nos foi franqueada.

Pesquisadores de diversas vertentes e instituiçóes atenderam ao nosso chamado para promover pesquisas que trazem impacto real na sociedade. Agradecemos aos pesquisadores que encaminharam os seus estudos, incluindo os que infelizmente não foram aprovados, mas sobretudo aos que possuem os trabalhos apensados a esta edição. $\mathrm{O}$ processo de revisão precedente à aprovação dos artigos contou com um fluxo intenso de comunicação entre os autores, os editores convidados e os revisores anônimos. Nosso muito obrigado por não terem desistido do processo.

Outrossim, gostaríamos encarecidamente de agradecer aos revisores anônimos, que executaram um valioso trabalho de exímio profissionalismo e comprometimento com a produção acadêmica de alta qualidade e rigor. Sem a generosidade de doação de tempo dos revisores nas múltiplas rodadas de avaliação, nada poderia ter sido feito. Registre-se o nosso muito obrigado por terem nos possibilitado levar este projeto adiante.

E é com muito orgulho que apresentamos a seguir os trabalhos que compóem esta edição especial.

\section{Uma aplicação do lasso quantílico geograficamente ponderado ao seguro de índice climático}

Esse artigo de autoria dos pesquisadores Daniel Lima Miquelluti, Vitor Augusto Ozaki e David José Miquelluti mostra que o lasso quantílico geograficamente ponderado (GWQlasso) é uma alternativa para o enfrentamento dos riscos encontrados no mercado de seguro agrícola no Brasil. Os resultados obtidos pelos autores apontaram que esse dispositivo tem a possibilidade de superar os benefícios protetivos decorrentes do tradicional seguro de produtividade agrícola.
Esse trabalho tem relevância ímpar para a pesquisa atuarial no Brasil, pois conjuga de forma rigorosa frentes como risco climático, inovação mercadológica e a esperada prescrição de quais caminhos podem servir como alternativas para os agentes de mercado na formatação de novos arranjos securitários.

\section{MAC: Uma proposta para metas atuariais consistentes em fundos de pensão}

O estudo desenvolvido pelos pesquisadores Sandro de Azambuja e Carlos Heitor Campani traz uma nova proposta para formação de metas atuariais compatíveis (MAC) com a rentabilidade dos investimentos auferidos por planos previdenciários. As conclusóes do estudo evidenciam que a Superintendência Nacional de Previdência Complementar (Previc) conseguiria aperfeiçoar o ecossistema normativo das entidades fechadas de previdência complementar por meio da adoção do MAC.

Trata-se de um artigo essencial para a indústria de previdência privada no Brasil porque captura a complexidade que as entidades de previdência complementar vêm encontrando atualmente para alcançarem as metas atuariais dos planos de pensão, em face do contexto restritivo que possuem para a gestão dos seus portfólios de investimentos. Não obstante, o artigo não se cinge ao campo da apresentação do problema, mas oferece a ele uma alternativa de soluçáo.

\section{Incerteza das provisões de sinistros a partir da análise das demonstrações contábeis}

O artigo de autoria dos pesquisadores Roberto Bomgiovani Cazzari e Guilherme Rodovalho Fernandes Moreira analisou a suficiência das provisóes técnicas de companhias brasileiras de seguros privados. A partir das demonstraçôes financeiras públicas das seguradoras, os autores trazem evidências de falta de padronização dos critérios de divulgação das informaçóes públicas e sinalizam que essas empresas podem incorrer em gerenciamento de resultados.

Esse estudo lança luz sobre os números contábeis que, performados por meio de critérios e parâmetros atuariais, podem desequilibrar os interesses dos diversos agentes interessados na continuidade da seguradora no longo prazo. Afinal, enquanto as provisóes técnicas insuficientes colocam em risco a solvência dessas entidades, saldos superestimados de provisionamentos deprimem os lucros contábeis, afetando principalmente os dividendos dos acionistas. 
Seguro garantia em infraestrutura no Brasil: Perspectivas de custos de transação e teoria da agência

O trabalho de autoria dos pesquisadores Tulio Henrique Moreira Marques, Mario Henrique Ogasavara e Frederico Araujo Turolla apresenta uma análise do seguro garantia no enredo de projetos de infraestrutura no Brasil. Os autores, com base em um estudo de dados primários coletados por meio de entrevistas, demonstram que conflitos de agência e elevados custos de transação prejudicam o desenvolvimento desse mercado.

A relevância desse estudo reside na demonstração de aspectos pontuais que impedem o avanço do seguro garantia. Outrossim, o material ainda demonstra forte alinhamento com a teoria geral de seguros, a qual preconiza a ideia geral de que, sob condiçóes de risco moral e seleção adversa, não há estímulos para o incremento e para o fortalecimento de determinados nichos securitários.

\section{REFERÊNCIAS}

Afonso, L. E. (2020). The actuarial science editorship of the Accounting \& Finance Review: Some general considerations. Revista Contabilidade \& Finanças, 31(82), 9-13. https://doi.org/10.1590/1808-057x202090320

Afonso, L. E., \& Carvalho, J. V. F. (2021). Show do trilhão no RGPS? Quantificando os aspectos fiscais e distributivos da reforma da previdência do governo Bolsonaro. Revista Brasileira de Economia, 75(2), 1-20. Retrieved from https://bibliotecadigital.fgv.br/ojs/index.php/rbe/article/ view/80203

Areias, C. A. C., \& Carvalho, J. V. F. (2021). Reinsurance in the supplementary health: A counterfactual study on the impacts of reinsurance treaties adoption by healthcare plans operators in Brazil. Brazilian Business Review, 18(2), 217-235. https://doi.org/10.15728/bbr.2021.18.2.6

Bispo, M. S. (2022). Reflecting on contemporary administration. Revista de Administraçâo Contemporânea, 26(1), e210203. https://doi.org/10.1590/1982-7849rac2022210203.en

\section{Persistência e reação do mercado aos resultados contábeis na indústria internacional de seguros}

O trabalho de autoria do pesquisador Renê Coppe Pimentel analisou a persistência dos lucros numa amostra cross-country composta por seguradoras. Os resultados indicam que o fluxo de caixa das entidades pesquisadas é consideravelmente mais constante do que os resultados contábeis e que a razão para tal discrepância se daria pelos elementos vinculados ao regime de competência contidos nos lucros/prejuízos.

A despeito da importância dos resultados trazidos pelo pesquisador para aquilo que se convencionou chamar de positive accounting theory, os achados indicam que o tratamento contábil aplicável às seguradoras tem produzido, ao menos em certa medida, um descolamento dos fluxos de caixa dos fluxos de lucro dessas entidades. Referida conjectura pode ser, inclusive, vista como uma mostra da importância de se repensar a contabilidade das seguradoras à luz da qualidade informacional dos relatórios financeiros, especialmente às vésperas da implementação da norma internacional de contabilidade para entidades que emitem contratos de seguros: o IFRS 17.

Fazemos votos de ótima e inspiradora leitura a todos!

Broberg, M. (2020). Parametric loss and damage insurance schemes as a means to enhance climate change resilience in developing countries. Climate Policy, 20(6), 693-703. https://doi.org/10.1080/14693062.2019.1641461

Cipriani, G. P., \& Fioroni, T. (2019). Endogenous demographic change, retirement, and social security. Macroeconomic Dynamics, 25(3), 609-631. https://doi.org/10.1017/S1365100519000269

Cole, S. (2015). Overcoming barriers to microinsurance adoption: Evidence from the field. The Geneva Papers on Risk and Insurance - Issues and Practice, 40(4), 720-740. https://doi.org/10.1057/gpp.2015.12

Euphasio Junior, J. W., \& Carvalho, J. V. F. (2022). Reinsurance and solvency capital: Mitigating insurance companies' ruin probability. Revista de Administração Contemporânea, 26(1), e200191. https://doi.org/10.1590/1982-7849rac2022200191.en 
Flores, E., Carvalho, J. V. F., \& Sampaio, J. O. (2021). Impact of interest rates on the life insurance market development: Cross-country evidence. Research in International Business and Finance, 58, 101444. https://doi.org/10.1016/j.ribaf.2021.101444

Lin, X., \& Kwon, W. J. (2020). Application of parametric insurance in principle-compliant and innovative ways. Risk Management and Insurance Review, 23(2), 121-150. https://doi.org/10.1111/rmir.12146

Mendes-da-Silva, W., Lucas, E. C., \& Carvalho, J. V. F. (2021). Flood insurance: The propensity and attitudes of informed people with disabilities towards risk. Journal of Environmental Management, 294, 113032. https://doi.org/10.1016/j.jenvman.2021.113032

\section{Autoria}

\section{João Vinícius de França Carvalho*}

Universidade de São Paulo, Faculdade de Economia, Administração, Contabilidade e Atuária

Av. Luciano Gualberto, no 908, Butantá, 05508-010, São Paulo, SP, Brasil.

E-mail: jvfcarvalho@usp.br

(D) https://orcid.org/0000-0002-1076-662X

\section{Eduardo Flores}

Universidade de Sáo Paulo, Faculdade de Economia, Administração, Contabilidade e Atuária

Av. Luciano Gualberto, no 908, Butantã, 05508-010, São Paulo, SP, Brasil.

E-mail: eduardoflores@usp.br

(D) https://orcid.org/0000-0002-5284-5107

\section{Emiliano A. Valdez}

University of Connecticut

341 Mansfield Road U1009, 06269-1009, Storrs, Connecticut, EUA.

E-mail: emiliano.valdez@uconn.edu

(D) https://orcid.org/0000-0003-4037-8385

* Autor Correspondente

\section{Conflito de Interesses}

Os autores informaram que não há conflito de interesses.

\section{Direitos Autorais}

A RAC detém os direitos autorais deste conteúdo.

\section{Verificação de Plágio}

A RAC mantém a prática de submeter todos os documentos aprovados para publicação à verificação de plágio, mediante o emprego de ferramentas específicas, e.g.: iThenticate.
Quan, Z., \& Valdez, E. A. (2018). Predictive analytics of insurance claims using multivariate decision trees. Dependence Modeling, 6(1), 377-407. https://doi.org/10.1515/demo-2018-0022

Rensi, R. T., \& Carvalho, J. V. F. (2021). Operation car wash: Impacts on the executives' liability insurance market. Revista de Administração Contemporânea, 25(2), e190386. https://doi.org/10.1590/1982-7849rac2021190386.en

Xu, M., \& Hua, L. (2019). Cybersecurity insurance: Modeling and pricing. North American Actuarial Journal, 23(2), 220249. https://doi.org/10.1080/10920277.2019.1566076

\section{CORPO EDITORIAL CIENTÍFICO E EQUIPE EDITORIAL PARA ESTA EDIÇÃO:}

\section{Conselho Editorial}

Anielson Barbosa da Silva (UFPB, João Pessoa, PB, Brasil) Antonio Carlos Gastaud Maçada (UFRGS, Porto Alegre, RS, Brasil) Ely Laureano Paiva (FGV, São Paulo, SP, Brasil)

Rogério Hermida Quintella (NPGA/UFBA, Salvador, BA, Brasil) Valmir Emil Hoffmann (UnB, Brasília, DF, Brasil)

\section{Editor-chefe}

Marcelo de Souza Bispo (UFPB, João Pessoa, PB, Brasil)

\section{Editores Associados}

Ariston Azevedo (UFRGS, Porto Alegre, RS, Brasil)

Carolina Andion (UDESC, Florianópolis, SC, Brasil)

Denize Grzybovski (UPF, Passo Fundo, RS, Brasil)

Eduardo da Silva Flores (FEA/USP, São Paulo, SP, Brasil)

Elisa Yoshie Ichikawa (UEM, Maringá, PR, Brasil)

Emílio José M. Arruda Filho (UNAMA, Belém, PA, Brasil)

Evelyn Lanka (Cranfield School of Management, Bedford, Reino Unido)

Fernando Luiz Emerenciano Viana (Unifor, Fortaleza, CE, Brasil) Gaylord George Candler (University of North Florida, Jacksonville, Florida, EUA)

Gustavo da Silva Motta (UFF, Niterói, RJ, Brasil)

Keysa Manuela Cunha de Mascena (Unifor, Fortaleza, CE, Brasil) Ludmila de Vasconcelos Machado Guimarães (CEFET-MG, Belo Horizonte, MG, Brasil)

Natália Rese (UFPR, Curitiba, PR, Brasil)

Orleans Silva Martins (UFPB, João Pessoa, PB, Brasil)

Pablo Isla Madariaga (Universidad Técnica Federico Santa María, Chile)

Paula Castro Pires de Souza Chimenti (UFRJ/Coppead, Rio de Janeiro, Brasil)

Rafael Chiuzi (University of Toronto Mississauga, Mississauga, ON, Canadá)

Sidnei Vieira Marinho (Univali, São José, SC, Brasil) 


\section{Corpo Editorial Científico}

André Luiz Maranhão de Souza-Leão (UFPE, Recife, CE, Brasil) Aureliano Angel Bressan (CEPEAD/UFMG, Belo Horizonte, MG, Brasil)

Bryan Husted (York University, Canadá)

Carlos M. Rodriguez (Delaware State University, EUA)

Cristiana Cerqueira Leal (Universidade do Minho, Portugal)

Diógenes de Souza Bido (Mackenzie, São Paulo, SP, Brasil)

Erica Piros Kovacs (Kelley School of Business/Indiana University, EUA)

Elin Merethe Oftedal (University of Stavanger, Noruega)

Fábio Frezatti (FEA/USP, São Paulo, SP, Brasil)

Felipe Monteiro (INSEAD Business School, EUA)

Howard J. Rush (University of Brighton, Reino Unido)

James Robert Moon Junior (Georgia Institute of Technology, EUA)

John L. Campbell (University of Georgia, EUA)

José Antônio Puppim de Oliveira (United Nations University, Yokohama, Japão)

Julián Cárdenas (Freie Universität, Berlin, Alemanha)

Lucas A. B. de Campos Barros (FEA/USP, São Paulo, SP, Brasil)

Luciano Rossoni (UniGranRio, Rio de Janeiro, RJ, Brasil)

M. Philippe Protin (Université Grenoble Alpes, França)

Paulo Estevão Cruvinel (Embrapa Instrumentação, São Carlos, SP, Brasil)
Rodrigo Bandeira de Mello (Merrimack College, EUA)

Rodrigo Verdi (MIT Massachusetts Institute of Technology, Cambridge, EUA)

Valter Afonso Vieira (UEM, Maringá, PR, Brasil)

Wagner A. Kamakura (Jones Graduate School of Business, Rice University, Houston, EUA)

\section{Editoração}

Diagramação e normas da APA: Kler Godoy (ANPAD, Maringá, Brasil); Simone L. L. Rafael (ANPAD, Maringá, Brasil).

Periodicidade: Publicação contínua.

Circulação: Acesso totalmente gratuito.

\section{Indexadores, Diretórios e Rankings}

Scielo, Redalyc, DOAJ, Latindex, Cengage/GALE, Econpapers, IDEAS, EBSCO, Proquest, SPELL, Cabell's, Ulrichs, CLASE, Index Copernicus International, Sherpa Romeo, Carhus Plust, Academic Journal Guide (ABS), DIADORIM, REDIB, Sumários.org, ERIHPlus, EZB, OasisBR, IBZ Online, WorldWideScience, Google Scholar, Citefactor.org, MIAR, Capes/Qualis. 